\title{
Does Relative Location Matter for Bilateral Trade Flows? An Extension of the Gravity Model
}

\author{
Beata K. Smarzynska \\ The World Bank
}

\begin{abstract}
This study extends the gravity model to include a new measure of the trading partners' location relative to other countries. The proposed measure is close in spirit to the theory of gravity, since it is based on the concept of the world trade center. The measure is statistically significant when the gravity equation is estimated using the intra-OECD trade flows. The results indicate that two countries located at the periphery rely more on bilateral trade than their centrally located counterparts. The study shows that omitting the location measure influences the estimated effects of regional country groupings in a systematic manner.
\end{abstract}

- JEL Classifications: F10, F15

- Key Words: International Trade, Gravity Model, Regional Integration, Geography

\section{Introduction}

The recently observed trend towards regional trade agreements as well as the economic and political transformation of Central and Eastern Europe, which initiated the integration of former communist countries into the world trading system, have revitalized the interest in the gravity model of international trade. The gravity model performs very well in predicting bilateral trade flows and

\footnotetext{
*Corresponding address: Beata K. Smarzynska, The World Bank, 1818 H St, NW, MSN MC3-303, Washington, DC 20433, USA. Tel: +1-202-458-8485, Fax: +1-202-522-1159, E-mail: bsmarzynska@worldbank.org (C)2001-Center for International Economics, Sejong Institution, All Rights Reserved.
} 
therefore is often used to estimate potential import and export flows, to examine trade diverting and creating effects of preferential trade agreements and to address other policy questions.

While predictions of the standard gravity equation rely on the economic size of the trading countries and the distance between them, the standard form of the model completely ignores the impact of the countries' location relative to all potential trading partners. Even though one of the model's fathers, Linnemann (1966), created an index measuring how favorable a country's location was for purposes of international trade and the relative location was formally dealt with by Anderson (1979) and Bergstrand (1985, 1989), in the empirical literature inspired by the gravity model this issue has been completely ignored.

Only recently this question has been raised again. Polak (1996) brought to our attention some troublesome characteristics of the gravity model arising from ignoring the impact of a country's relative location. Deardorff (1998) derived the gravity equation from two extreme cases of the Heckscher-Ohlin model and showed that bilateral export volume is influenced not only by the absolute distance between the two economies, but also by their geographical location relative to all other countries. Frankel and Wei (1998) took this point into account when mapping out the current pattern of regionalization and assessing the impact of currency links within some major groupings on intragroup trade.

This study explores a new method of describing the trading partners location relative to all other countries. The proposed measure is the closest in spirit to the theory of gravity, since it is based on the concept of the world trade gravity center (WTC, hereafter). A version of the gravity model including the trading partners' distance from the WTC is estimated using the intra-OECD trade figures, and the results are compared with those of the standard gravity equation. The relative distance measure is statistically significant and contributes to a small improvement in terms of goodness-of-fit and accuracy of predictions relative to the standard model. The hypothesis that two countries located away from potential trading partners tend to be more reliant on trade with each other than a pair of countries located close to the center is tested and confirmed by the data.

Inspired by Polak's (1996) criticism of using dummy variables to assess the effects of regional trade agreements, this study explores how such estimates are affected by leaving out the measure of relative location. We find that not taking into account the relative location influences the estimated effects of regional trading blocs in a systematic manner. Omitting the relative location leads to an 
overestimate of trade flows between the members of a country grouping located away from the WTC and an underestimate in the case of a centrally located trading bloc. For instance, while the standard gravity equation indicates that two East Asian countries trade with each other almost twice as much as other countries characterized by the same size and bilateral distance, the extended version of the model reduces the estimated increase in trade to sixty-seven percent. Thus the results of this study indicate that leaving out the relative distance may lead to incorrect conclusions about the impact of regional groupings and therefore provide misleading answers to policy questions.

This paper is organized in the following manner. Section II reviews the literature on the theoretical aspects and applications of the standard gravity model. In Section III the shortcomings of the standard model are addressed, and the concept of the world trade center is introduced. Section IV presents the estimation results. Section $\mathrm{V}$ addresses the consequences of leaving out the location measure. Section VI concludes the study.

\section{Related Literature}

The gravity model is based on a concept borrowed from the physical sciences, where the gravity force is directly proportional to the mass of two bodies and inversely proportional to the distance between them. When applied to economics, the gravity equation describes a bilateral trade flow as positively related to the economic size of the two countries and negatively related to the distance between them.

Tinbergen (1962) was the first to use the gravity equation to study international trade flows. Linnemann (1966) extended the model by adding additional variables and trying to explain the theoretical underpinnings of the equation in terms of a Walrasian general equilibrium system. Further attempts to justify the model theoretically include Leamer and Stern (1970) who derived the gravity equation from a probability model of transactions and Anderson (1979) who assumed product differentiation. Bergstrand $(1995,1989)$ derived a version of the gravity equation under the assumptions of monopolistic competition and product differentiation among firms, not countries.

Recently, Deardorff (1998) derived versions of the gravity equation from two extreme cases of the Heckscher-Ohlin model. The first case involves free trade in homogenous products with the producers and consumers indifferent between 
choosing among the various trading partners. If this indifference is randomly resolved, a simple frictionless gravity equation is obtained under the assumption of identical homothetic preferences or alternatively under the assumption of demands being uncorrelated with supplies. The second case, including countries producing distinct goods and Cobb-Douglas or CES preferences, again leads to a version of the gravity equation. Deardorff concludes that the gravity model is consistent with a large class of standard trade models.

The two main applications of the gravity model are assessing regional biases in international trade and predicting potential trade flows. An example of the former approach is a study by Frankel and Wei (1998) in which a gravity equation is used to map out the current pattern of regionalization in trade, while the latter application can be found, for example, in Hamilton and Winters (1992) and Baldwin (1994) who examine the impact of changes in the former communist countries on world trade. Further applications of the model include estimating the effect of exchange rate variability on trade (Frankel and Wei, 1998) and exploring the role of trade in spreading the benefits of innovation (Eaton and Kortum, 1997).

In its simplest form, the gravity equation reads:

$$
\ln T_{i j}=\beta_{0}+\ln \left(G D P_{i} \cdot G D P_{j}\right)+\beta_{2}\left(G D P P C_{i} \cdot G D P P C_{j}\right)+\beta_{2} \ln \left(\text { Distance }_{i j}\right)
$$

where $T_{i j}$ represents a trade flow from country $i$ to country $j, G D P$ stands for the total Gross Domestic Product and GDPPC for the Gross Domestic Product per capita. It is often argued that larger and richer countries (i.e., countries with high $G D P$ and $G D P P C$, respectively) have more varieties of goods to offer, and if consumers have a preference for variety, they are more likely to trade with such partners. Additionally, well-off economies can afford to import more goods. More developed countries also tend to be more specialized and therefore rely on trade to a larger extent. Furthermore, richer countries often have better infrastructure: ports, transportation routes, so they are better equipped to engage in exchange of goods.

Distance $_{i j}$ denotes the distance between the trading partners, either between their capital cities or the great circle distance between the major ports. Shipping costs are the main reason why distance enters the gravity equation. Proximity reduces the transportation costs, time lags, decreases the magnitude of spoilage as well as the cost of gathering information about the partners legal and administrative procedures. Countries located close to each other's are more likely to have a long history of bilateral trade, which gives them a better understanding of each other's customs and tastes. 
The gravity equation may also include dummy variables for adjacency, common language or preferential trade agreements (PTAs). Neighboring countries often enjoy special commercial ties for historical reasons, while common language reduces transaction costs, facilitates better understanding of commercial practices, laws and regulations, as well as gives better understanding of partner's culture and tastes. PTAs result in lower transaction costs due to reduced trade barriers and simpler administrative requirements.

\section{Concept of the World Trade Center}

The literature focusing on theoretical underpinnings of the gravity equation shows that in addition to the economic size and the distance between two countries, the geographical location of a country pair relative to all potential trading partners affects their bilateral trade. The gravity equation derived by Anderson (1979) includes an income weighted average of bilateral transport costs facing an exporting country. Bergstrands $(1985,1989)$ version of the gravity model incorporates price weighted averages of bilateral transport costs for both the exporter and the importer. More specifically, Bergstrand's model (1985, equation 14) contains a price index that is equal to the summation of the bilateral prices that the exporter faces in all potential markets. Each bilateral price in equilibrium is in turn a function of the bilateral transport cost (or distance). Thus, this price index captures the exporter's location relative to all potential markets. Additionally, the equation contains a term capturing the importer's location with respect to its potential suppliers.

The gravity equation derived by Deardorff (1998) also contains both an index of importer's location relative to its various suppliers as well as an index reflecting the exporters geographic position with respect to its potential markets. Further, Deardorff's result indicates that the greater is the elasticity of substitution among goods, the more will trade between distant countries fall short of the gravity equation and the more will transactions between close countries exceed it.

The shortcomings of the standard gravity model, which does not take into account the relative location, are discussed in Polak (1996). He finds that the ratio of a country's actual total imports to those predicted by the gravity equation is negatively correlated with the Linnemann's index of relative location. ${ }^{1}$ Thus, the gravity model seems to underpredict the magnitude of total imports for countries located at the periphery and overpredict for those close to the center.

\footnotetext{
${ }^{1}$ The Linnemann index is defined as $1 / D_{i}$ where $D_{i}=\Sigma_{j}\left(\mathrm{GNP}_{j}^{0.8}\right.$ Population $_{\mathrm{j}}^{-.24}$ Distance $\left._{i j}\right)$.
} 
This study follows very closely the spirit of the theory of gravity and proposes an alternative measure of the trading partners' relative location. Unlike Polak (1996) and Frankel and Wei (1998), who use a location index equal to the sum of all bilateral distances weighted by partners' GDPs, we employ a two step procedure. First, we find the location of the world trade center and then we measure all distances with respect to the center. Also, while Polak suggests using only the importer's location and Frankel and Wei include the 'remoteness measure' for each trading partner separately, we calculate the relative location for a country pair rather than for a single economy.

The world trade center is found by summing the coordinates of midpoints between all country pairs and weighting them by the partners' GDPs. The relative location of a country pair is measured by the distance from the WTC to the midpoint between the two countries. The methodology for finding the position of the WTC and the relative distance is described in detail in Appendix I. The geographical location of the WTC depends on the number and selection of countries included in the sample. ${ }^{2}$ It should be stressed that the existence of the WTC should not be taken literally; rather, the concept of the center is meant to be a way of describing the geographical position of a pair of countries relative to all potential trading partners.

A simple example can illustrate the meaning of the world trade center. Suppose that there are two identical pairs of countries (in terms of the economic size and the distance between them), with one pair located close to the center and the other pair being far away. Then, we expect that the two countries at the periphery will be more dependent on trading with each other than their centrally located counterparts, since they face a more limited choice of potential trading partners nearby. In contrast to Frankel and Wei (1998), we are able to test this hypothesis by estimating a model based on trade shares rather than absolute trade flows. The next section addresses this point in more detail.

\section{Model and Estimation Results}

\section{A. Model}

The location of a pair of countries relative to the WTC can affect their goods

\footnotetext{
${ }^{2}$ When twenty-two $O E C D$ countries are taken into account, which is the sample used in this study, the WTC is located in Greenland. For comparison, when only the European $O E C D$ members are included, the center moves to a location slightly south of Luxembourg.
} 
exchange in two ways. First, countries at the periphery may be in general less reliant on trade, i.e., they may trade less in absolute terms than economies of the same size located closer to the center. ${ }^{3}$ At the same time, two peripheral countries may be more dependent on trading with each other, i.e., the share of their bilateral trade flows in their total trade may increase the further away they are from the center. Note, however, that this share is likely to go down with the growing distance between the two trading partners. If we include the variable representing the distance of a country pair from the center, its sign will be ambiguous, since it will be a sum of two effects, one of which is positive and the other negative. ${ }^{4}$ Therefore, in order to determine whether our hypothesis about the impact of the relative location on trade is correct, we need to estimate a model based on bilateral trade shares rather than on absolute bilateral flows.

Thus, our model has the following form:

$$
\begin{gathered}
\ln \frac{B_{i j}}{T_{i}+T_{j}}=\beta_{0}+\beta_{1} \ln \left(\frac{G D P_{i}}{G D P T} \cdot \frac{G D P_{j}}{G D P T}\right)+\beta_{2} \ln \left(\frac{G D P P_{i}}{G D P P C T} \cdot \frac{G D P P_{j}}{G D P P C T}\right)+ \\
\beta_{3} \ln \left(\text { Distance }_{i j}\right)+\beta_{4} \ln \left({\text { WTC } \left.\text { distance }_{i j}\right)}^{\text {G }}\right)
\end{gathered}
$$

where $B_{i j}$ stands for bilateral trade between countries $i$ and $j, T_{i}$ is the sum of country $i$ 's imports and exports, GDP is the Gross Domestic Product, GDPPC the

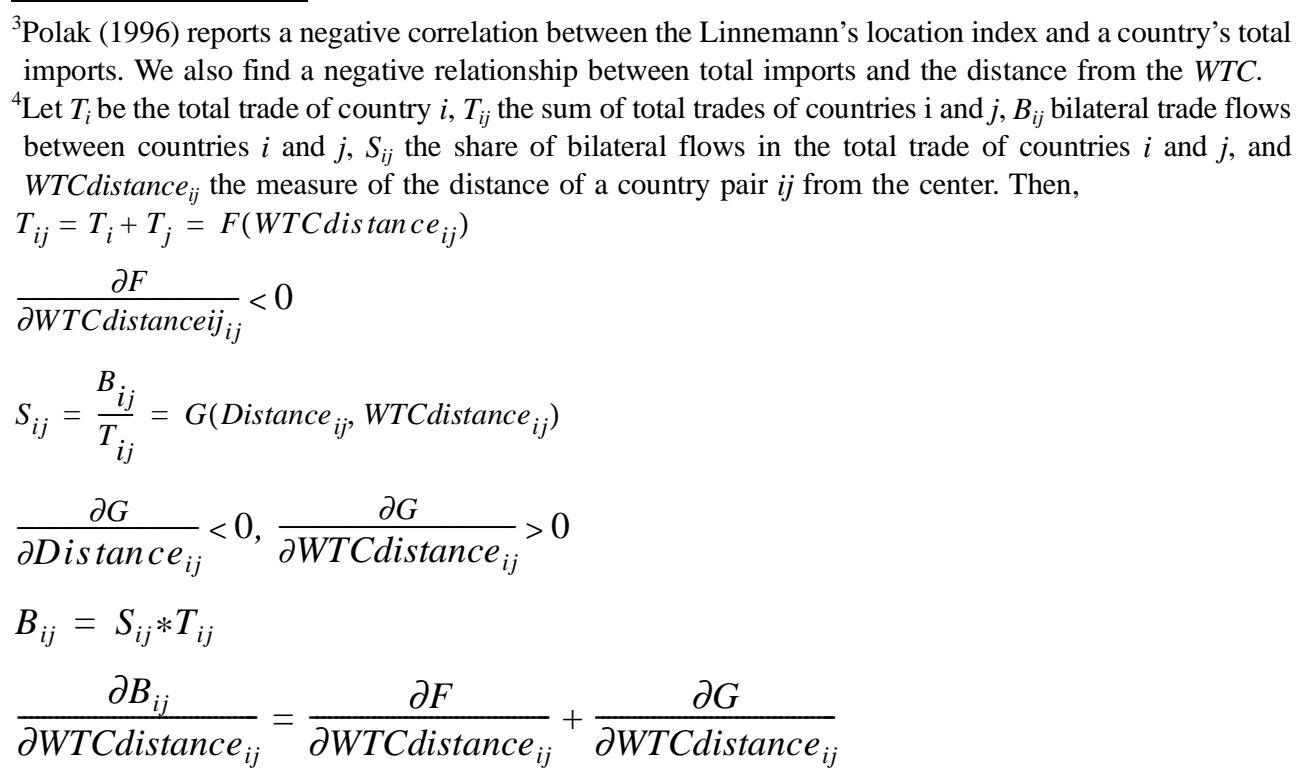

Thus, the sign of the derivative of the bilateral trade flow with respect to the relative location of a country pair is ambiguous. 
Gross Domestic Product per capita, GDPT is the sum of the GDPs of all countries in the sample, while GDPPCT is equal to GDPT divided by the total population of countries in the sample. Distance $_{i j}$ represents the great circle distance between the major ports, while WTCdistance ${ }_{i j}$ captures the location of the partners relative to the WTC.

For reasons explained before, positive coefficients on the GDP terms are anticipated. Distance, on the other hand, is expected to bear a negative sign. If our hypothesis relating the location of two countries to their trade flows is valid, the relative distance will have a positive coefficient. The regional dummy variables are likely to have positive signs as well.

\section{B. Data}

In our empirical analysis, we employ data on trade in manufactured goods reported in the $O E C D$ Impex database. ${ }^{5}$ We use annual import flows of twentytwo $O E C D$ countries. ${ }^{6}$ The flows for Belgium and Luxembourg are reported jointly. Figures on Germany pertain to West Germany only. All trade flows are expressed in 1985 US dollars. Industrial Producer Price Index from the IMF International Financial Statistics (1995) has been used as a deflator. We include figures on total trade between 21 countries in the eleven-year-long 1980-1990 period, which amounts to $21 *(21-1) * 11 / 2=2310$ observations. The values of Turkish imports from New Zealand in 1980-82 are reported as equal to zero dollars. Since zero values may create problems in the case of panel data, the smallest value of import flow found in the sample equal to seven thousand dollars is used instead.

Data on GDPs come from Penn World Table and are expressed in 1985 US dollars. In case of Belgium and Luxembourg, the sum of total GDPs and the average of GDPs per capita are used. The major ports of each country are chosen according to The Europa World Yearbook (1996). The distance variable comes from Caney and Reynolds (1965) and is equal to the great circle distance between the closest pair of major ports. In the case of landlocked Switzerland, it is assumed

\footnotetext{
${ }^{5}$ The following categories of manufactured goods have been included (in SITC classification): beverages (11), manufactured tobacco (122), refined petroleum products (334), residual petroleum products (335), chemicals (5), manufactured goods (6), machinery and transport equipment (7), miscellaneous manufactured articles (8).

${ }^{6}$ The following countries are included: Canada, US, Japan, Australia, New Zealand, Belgium and Luxembourg, Denmark, Finland, France, Germany, Greece, Ireland, Italy, the Netherlands, Norway, Portugal, Spain, Switzerland, Sweden, Turkey, UK.
} 
that ports of other countries in the region are utilized or the distance between capital cities is used when trade takes place with neighboring countries. The relative distance is calculated following the procedure described in Appendix I.

\section{Estimation Results}

First, for the purpose of comparison we estimate the standard gravity equation using the OLS model. The results are presented in the first column of Table 1 in Appendix II. Next, we estimate the extended version of the gravity equation that includes the relative distance measure:

$$
\begin{aligned}
& \ln \frac{B_{i j, t}}{T_{i}+T_{j}}=\beta_{0}+\beta_{1} \ln \left(\frac{G D P_{i}}{G D P T} \cdot \frac{G D P_{j}}{G D P T}\right)+\beta_{2} \ln \left(\frac{G D P P C_{i}}{G D P P C T} \cdot \frac{G D P P C_{j}}{G D P P C T}\right)+ \\
& \beta_{3} \ln \left(\text { Distance }_{i j, t}\right)+\beta_{4} \ln \left(\text { WTCdistance }_{i j}\right)+\varepsilon_{o k}
\end{aligned}
$$

In both cases, all coefficients have the expected signs and are significant at the one percent level. The goodness-of-fit as measured by the adjusted $R^{2}$ is satisfactory (reaching .72 and .73, respectively). The positive and statistically significant coefficient on the relative distance confirms our hypothesis about the effect of location of a country pair on the bilateral trade share.

Further, the results indicate that large (in terms of economic size, i.e., total GDP share) and rich (i.e., enjoying a high per capita GDP relative to the $O E C D$ average) countries tend to trade more with each other, all other things being equal. The GDPs per capita of trading partners, however, seem to have a greater impact on trade shares than the total GDP shares. As expected, the greater the distance between the partners, the lower the bilateral trade as a share of total trade. As was mentioned in the previous section, larger distance increases shipping and spoilage costs, thus discouraging the exchange of goods.

The results confirm our hypothesis that the location of trading partners relative to the WTC affects their exchange of goods. The positive coefficient on the relative distance indicates that for a pair of countries located at the periphery the share of bilateral trade in total trade is higher than for countries closer to the center, all other things being equal. Thus, economies situated away from the majority of potential trading partners rely more on countries in their region, while economies located more centrally enjoy more even trade ties with their partners. Including the measure of the relative distance contributes to a slight improvement in the goodness-of-fit measure. It also increases the accuracy of model predictions as 
measured by the average ratio of actual to predicted trade share. ${ }^{7}$

\section{An Improved Specification}

It is plausible that some pairs of countries enjoy special commercial ties, and their trade flows are disproportionately large. It may be caused by historical reasons and cultural ties, sharing the common border, common language, the same religion or enjoying especially convenient transportation routes. On the other hand, some countries may be considered to be more closed to trade, while others may be engaging in minor trade wars. Therefore, it is likely that there exist some individual effects specific to each pair of countries. Since a panel dataset is available for estimation, it is wise to exploit its properties to address these issues.

Another benefit of applying a panel data estimation technique is that the terminal costs which might constitute a large portion of transportation costs (and which will not be proportional to the distance between the trading partners) will be captured by the country-pair-specific random effect.

Thus, we proceed to estimate a random effect model in the following form:

$$
\begin{aligned}
& \ln \frac{B_{i j, t}}{T_{i, t}+T_{j, t}}=\beta_{0}+\beta_{1} \ln \left(\frac{G D P_{i, t}}{G D P T_{t}} \cdot \frac{G D P_{j, t}}{G D P T_{t}}\right)+\beta_{2} \ln \left(\frac{G D P P C_{i, t}}{G D P P C T_{t}} \cdot \frac{G D P P C_{j, t}}{G D P C T_{t}}\right)+ \\
& \beta_{4} \ln \left(\text { Distance }_{i j, t}\right)+\beta_{4} \ln \left(\text { WTCdistance }_{i j, t}\right) u_{i j}+\varepsilon_{i j, t}
\end{aligned}
$$

where $u_{i j}$ is the random disturbance constant through time and specific to each pair of countries.

Again, the first column of Table 2 lists the estimation results of the standard gravity equation, while the second column presents the results of the model including the distance to the WTC. All coefficients are significant at the one percent level and have the same signs as the least square estimates. The magnitudes are also similar to those presented in the first table, with the exception of GDP per capita whose coefficient decreased in size and the coefficient on the relative distance which became larger.

The results indicate that the economic size and the development level of the trading partners have a significant and positive effect on their trading relationship. If the product of total GDP shares of the trading partners increases by one percent, their bilateral trade share will rise by circa .45 percent. A one percent increase in

\footnotetext{
${ }^{7}$ Note that we also experimented with using trade weights instead of GDP weights when calculating the distance to the WTC. It did not lead, however, to significantly different results.
} 
the product of GDPs per capita produces a similar result. As was mentioned before, larger and more developed countries often offer a wider variety of goods, which makes trading with them more attractive. Such countries can also offer the most advanced goods that tend to be more appealing to the consumers.

The distance between partner countries has a significant impact on their trade flows. A one percent increase in the distance lowers the trade share by almost .8 percent. The location of a pair of countries relative to the WTC also matters for their goods exchange. A one percent increase in the relative distance increases their trade share by .38 percent. Including the distance from the WTC in the estimation changes the coefficients of the other variables only slightly, at the same time it leads to a slight increase in the adjusted R-squared and some improvement in the accuracy of the model's predictions.

\section{Consequences of Leaving out the Location Measure}

In this section, we examine the consequences of leaving out the location measure from the gravity equation. In his discussion of Frankel, Stein and Wei (1994), Polak (1996) points out that "the apparent evidence of 'regional trading arrangements' among countries that do not in fact have trading arrangements is attributable to a mis-specification inherent in the traditional gravity model" (p. 534). In other words, he suggests that some of the findings of Frankel et al. may be a result of omitting a measure of relative location.

To address the issue, we first attempt to reproduce the results of three cross section regressions presented by Frankel et al. The regressions, in the form presented below, are estimated using the OLS method:

$$
\begin{gathered}
\log \left(T_{i j}\right)=\alpha+\beta_{1} \log \left(G N P_{i} G N P_{j}\right)+\beta_{2} \log \left(G N P_{i} / \text { pop }_{i} G N P_{j} / \text { pop }_{j}\right)+ \\
\beta_{3+} \log \left(\text { Distance }_{i j}\right)+\beta_{4}\left(\text { Adjacent }_{i j}\right)+\gamma_{1}\left(\text { WH }_{i j}\right)+\gamma_{2}\left(\text { EAsia }_{i j}\right)+ \\
\gamma_{3}\left(A P E C_{i j}\right)+\gamma_{4}\left(E E C_{i j}\right)+\gamma_{5}\left(E F T A_{i j}\right)+u_{i j}
\end{gathered}
$$

where $T_{i j}$ represents the total trade flow between countries $i$ and $j$; the Adjacent dummy takes on the value of one if countries $i$ and $j$ share a common land border and zero otherwise; WH, EAsia, APEC, EEC, and EFTA are dummies for regional groupings standing for Western Hemisphere, East Asia, Asian Pacific Economic Cooperation, European Community and European Free Trade Agreement. Dummies with a subscript 2 are equal to one if both country $i$ and country $j$ are 
members of the group, and zero if it is not the case. Dummies with a subscript 1 take on the value of one if at least one partner is a member of the group, and zero otherwise.

Three tables in Appendix III contain the estimated equations for 1970, 1980 and 1990, respectively. Unfortunately, the dataset has been updated since the time Frankel and his colleagues worked on their study, and thus it is not possible to reproduce their results exactly. ${ }^{8}$ Each of the tables in Appendix III, therefore, contains the original results in the first column and our reestimation, which used the updated dataset, in the second column. ${ }^{9}$ The last column presents the estimates of a model including the relative location measure. The comparison of the second and third column shows that including the distance from the WTC does not change the signs or the significance levels of the standard components of the gravity equation, such as the GDP, the GDP per capita and the distance, and has a limited impact on the magnitudes of their coefficients. This is also the case with the adjacency dummy.

Including the relative distance does, however, affect the dummies for country groupings in a systematic manner. As we found earlier in this study, countries located far away from the center tend to rely to a larger extent on trade with each other. Thus, the standard version of the gravity model tends to underpredict the magnitude of trade flows between such countries. This is likely to be the case with East Asian economies. They are located far from the WTC and therefore tend to trade with one another more than what the standard gravity model would predict for them. ${ }^{10}$ If the relative distance is not included in the model, this effect is captured by the dummy variable. ${ }^{11}$

Indeed, when we include the distance from the WTC, the magnitude of dummies denoting that both trading partners are East Asian countries $\left(\right.$ EAsia $\left._{2}\right)$ goes down in all three regressions. Note that the dummies are significant in 1970

\footnotetext{
${ }^{8}$ The dataset has been generously supplied by Shang-Jin Wei.

${ }^{9}$ Note the difference in the number of observations used in the regressions presented in both columns. In case of our reestimation, we included only the observations for which data on all variables were available.

${ }^{10}$ The calculations of the WTC coordinates show that it was located in the southern part of Greenland in 1970 and moved east of Greenland during the following two decades. Therefore, we can consider East Asia as being far away from the center and the European Community and EFTA as centrally located.

${ }^{11}$ Note that we are discussing here the EAsia 2 dummy, which indicates whether both countries are part of the grouping. We are not going to elaborate on dummies pertaining to the membership of at least one country in the group (e.g., EAsia ${ }_{1}$ dummy), since in that case the expected impact of including the distance from the WTC in the regression is ambiguous.
} 
and 1980 but not in 1990. While the standard model predicts that the total trade between a pair of East Asian economies was ninety-seven percent higher in 1980 than what it would have been for countries of the same size and with the same bilateral distance, when the relative location is included this figure goes down to sixty-seven percent. ${ }^{12}$ Similarly, when the location measure is taken into account, the magnitude of $A P E C$ dummies decreases as well, which is not surprising since all $A P E C$ members except for the US and Canada are located far from the $W T C{ }^{13}$ The $A P E C_{2}$ dummies appear to be significant in all three regressions.

In the case of the two centrally located preferential trade arrangements, namely the European Community and EFTA, the opposite effect should be observed. Since both of these groups enjoy having many trading partners at close distance, they are able to trade with more countries that just those in their region. The standard gravity model thus should overpredict trade flows within each of these grouping and the dummy variables should present the effect of each PTA as lower than it is in reality. And this is indeed the case for the European Community in 1970, which is the only time when the dummy is significant in both the standard and the extended version of the model. We note again than the modified version of the gravity equation performs better in terms of goodness-of-fit and the accuracy of predictions.

We conclude that while contrary to Polak's (1996) argument the general findings of Frankel et al. (1994) are not changed by including the relative location measure in the gravity model, the magnitudes of the estimated effects of regional country groupings are affected by this change. Our results indicate that one should be very careful when interpreting the dummy variables for regional groups in a standard gravity model since they might be capturing the impact of members' relative location in addition to the trade effects of formal or informal trading arrangements.

\section{Conclusions}

In this study, we propose and test a new method of describing the location of two trading partners relative to all other countries. The new measure is based on the concept of the world trade gravity center and thus is very close in spirit to the theory of gravity. It is found to be statistically significant and it contributes to some improvement in the goodness-of-fit and accuracy of predictions. Additionally, we

\footnotetext{
${ }^{12} \operatorname{Exp}(.68)=1.97 ; \exp (.51)=1.67$

${ }^{13}$ APEC consists of Japan, Indonesia, Taiwan, Hong Kong, South Korea, Malaysia, Philippines, Singapore, Thailand, China, Australia, New Zealand, Canada and the US.
} 
find empirical support for the hypothesis that two countries located away from all potential trading partners tend to be more reliant on trade with each other than a pair of countries located close to the center.

Since the gravity model gives a good account of bilateral trade flows, it is often used to assess the effects of regional country groupings as well as other policy experiments. Our findings indicate that leaving out the relative distance affects the estimated impact of regional trade agreements on international trade flows. Thus neglecting to include the relative distance can lead to misleading conclusions on policy questions.

Date accepted: January 2001

\section{References}

Anderson, James E. (1979), "A Theoretical Foundation for the Gravity Equation," American Economic Review. 69, 106-116.

Baldwin, Richard E. (1994), Towards an Integrated Europe, Centre for Economic Policy Research.

Bergstrand, Jeffrey H. (1985), "The Gravity Equation in International Trade: Some Microeconomic Foundations and Empirical Evidence," Review of Economics and Statistics. 67, 474-81.

Bergstrand, Jeffrey H. (1989), “The Generalized Gravity Equation, Monopolistic Competition and the Factor-Proportions Theory in International Trade," Review of Economics and Statistics. 71, 143-153.

Caney. R.W. and J.E. Reynolds (1965), Reed's New Marine Distance Tables, London: Thomas Reed Publishers Limited.

Collins, S. and Dani Rodrik (1991), Eastern European and the Soviet Union in the World Economy. Washington, DC: Institute for International Economics,.

Deardorff, Alan V. (1998), "Determinants of Bilateral Trade: Does Gravity Work in a Neoclassical World?" in Jeffrey Frankel, ed. Regionalization of the World Economy. NBER and University of Chicago Press, 7-32.

Eaton, Jonathan and Samuel Kortum (1997), “Technology and Bilateral Trade,” NBER Working Paper 6253.

The Europa World Yearbook (1996), Rochester: England Europa Publications Limited. Frankel, J., E. Stein and S. Wei (1994), “Trading Blocs: The Natural, the Unnatural and the Super-Natural," Berkeley, CA: University of California Center for International and Development Research, CIDER, Working Paper C94-034.

Frankel, Jeffrey A. and Shang-Jin Wei (1998), "Regionalization of World Trade and Currencies: Economics and Politics" in Jeffrey Frankel, ed. Regionalization of the World Economy. NBER and University of Chicago Press, 189-226. 
Hamilton, Carl B. and L. Alan Winters (1992), "Opening up international trade with Eastern Europe," Economic Policy. 14, 78-113.

International Monetary Fund (1995), International Financial Statistics. Washington D.C. Leamer, Edward E. and Robert M. Stern (1970), Quantitative International Economics, Boston: Allyn and Bacon.

Linnemann, Hans (1966), An Econometric Study of International Trade Flows, Amsterdam: North-Holland.

Polak, Jacques (1996), "Is APEC a Natural Regional Trading Bloc? A Critique of the Gravity Model of International Trade," The World Economy. 19, 533-543.

Tinbergen, J. (1962), Shaping the World Economy: Suggestions for an International Economic Policy, New York: The Twentieth Century Fund.

\section{Appendix I}

\section{Finding the Gravity Center of the World Trade}

The following procedure is used in calculating the location of the WTC. First, the latitude and longitude of the major ports of countries in the sample are found. Let the latitude be denoted by $\Theta$ and longitude by $\Phi$. Both values are measured in degrees. The northern latitudes are expressed as positive numbers, while the southern as negative numbers. Similarly, eastern longitudes are assigned a positive value, while western a negative value.

Then, the location of each port, as described by its latitude and longitude, is converted from degrees into the Cartesian system of coordinates, where three values $(x, y$, and $z)$ describe the location of a point in space with respect to the system's origin. ${ }^{14}$ The well known trigonometric formulas are used to make the conversion:

$$
\begin{aligned}
& z=\sin \Theta \\
& y=\cos \Theta \sin \Phi \\
& x=\cos \Theta \cos \Phi
\end{aligned}
$$

Next, a midpoint for each pair of countries is found. Coordinates of a midpoint are simplesummarizes arithmetic averages of the Cartesian coordinates of the two ports considered relevant for the goods exchange between a particular pair of

\footnotetext{
${ }^{14}$ The systems origin may be thought of as the center of the globe.
} 
countries. That is $x^{\text {midpoint }}=\left(x^{i}+x^{j}\right) / 2$ and analogous formulas are used to find $y$ and $z$ coordinates. In order to assure that a midpoint is located on the surface of the globe (rather than inside the globe), its coordinates are divided by the length of the vector representing the midpoint. Thus a midpoint is the place located exactly half-way on the shortest route between the two trading partners.

The coordinates of the WTC are then calculated using the following formula:

$$
X^{W T C}=\sum_{j}\left(\frac{G D P_{j}}{G D P_{O E C D}} \sum_{i} X_{\text {midpoint }} G D P_{i j}\right)
$$

That is, the X-coordinate of the WTC is found by first summing the Xcoordinates of all midpoints between reporting country $j$ and its trading partners, weighting the coordinates by partner's GDPs, and then by adding these sums for all reporting countries, weighting them by the share of each reporting country in the total $G D P$ of the $O E C D$. The Y- and Z-coordinates are found in a similar manner. Again, the coordinates of the WTC are normalized by dividing by the length of the vector representing the center's location, which assures that the WTC is located on the surface of the globe. The Cartesian coordinates of the WTC can be converted into latitude and longitude, and the point can be located on the world map.

The last step of the procedure involves finding the arc distance between the midpoint of each country pair and the WTC. This is equivalent to calculating the great circle distance or the shortest route on the surface of the globe between the two locations. This distance, which will be denoted by the abbreviation WTCdistance, is computed for all pairs of countries in the sample using the standard formula found in calculus textbooks:

$$
\text { WTCdistance }=2 \operatorname{Rarcsin}\left(\frac{d}{2 R}\right)
$$

where $R$ is the length of the Earth radius expressed in nautical miles, and $d$ is the length of the segment connecting the midpoint with the WTC. This formula is derived from the fact that the arc distance is proportional to the angle between the vectors representing the locations of midpoint and the WTC.

Note that if a panel dataset is being used, the location of the WTC will vary slightly over time, since the GDP weights will be different each year. If a country experiences a dynamic GDP growth, it becomes a larger potential trading partner and thus influences the location of the WTC. This effect is captured by a time varying WTCdistance variable. 


\section{Appendix II}

Table 1. Ordinary Least Squares

\begin{tabular}{|c|c|c|}
\hline & $\begin{array}{l}\text { Dependent variable } \\
=\text { bilateral trade share }\end{array}$ & $\begin{array}{l}\text { Dependent variable } \\
=\text { bilateral trade share }\end{array}$ \\
\hline$\left(G D P_{i} / G D P T\right)^{*}\left(G D P_{j} / G D P T\right)$ & $\begin{array}{l}.4203 * * * \\
(.0094)\end{array}$ & $\begin{array}{l}.4386^{* * *} * \\
(.0094)\end{array}$ \\
\hline$\left(G D P P C_{i} / G D P T\right)^{*}\left(G D P P C_{j} / G D P T\right)$ & $\begin{array}{l}.6342 * * * \\
(.0308)\end{array}$ & $\begin{array}{l}.6575 * * * \\
(.0302)\end{array}$ \\
\hline Distance $_{\mathrm{ij}}$ & $\begin{array}{l}-.7146 * * * \\
(.0127)\end{array}$ & $\begin{array}{l}-.7836^{* * * *} \\
(.0143)\end{array}$ \\
\hline WTC distance $_{i j}$ & & $\begin{array}{l}.3227 * * * \\
(.0332)\end{array}$ \\
\hline Intercept & $\begin{array}{c}6.5133 * * * \\
(.1712)\end{array}$ & $\begin{array}{l}4.8723 * * * \\
(.2382)\end{array}$ \\
\hline No. Obs. & 2310 & 2310 \\
\hline R-sq & 0.72 & 0.73 \\
\hline Adj. R-sq & 0.72 & 0.73 \\
\hline Avg. Actual/Predicted Trade Share & 1.32 & 1.29 \\
\hline
\end{tabular}

Standard errors are reported in parentheses.

$* * *$ significant at $1 \%$ level.

Table 2. Random Effect Model

\begin{tabular}{|lcc|}
\hline & $\begin{array}{c}\text { Dependent variable } \\
\text { = bilateral trade share }\end{array}$ & $\begin{array}{c}\text { Dependent variable } \\
\text { =bilateral trade share }\end{array}$ \\
\hline$\left(G D P_{i} / G D P T\right)^{*}\left(G D P_{j} / G D P T\right)$ & $.4254^{* * *}$ & $.4480^{* * *}$ \\
$\left(G D P P C_{i} / G D P T\right)^{*}\left(G D P P C_{j} / G D P T\right)$ & $(.0291)$ & $(.0292)$ \\
& $.4239^{* * *}$ & $.4456^{* * *}$ \\
Distance $_{i j}$ & $(.0820)$ & $(.0810)$ \\
& $-.7145^{* * *}$ & $-.7965^{* * *}$ \\
WTC distance $_{i j}$ & $(.0396)$ & $(.0445)$ \\
& $.3834^{* * *}$ & $.3834 * * *$ \\
Intercept & $(.1005)$ & $(.1005)$ \\
No. Obs. & $6.5142^{* * *}$ & $4.5745^{* * *}$ \\
Adj. R-sq & $(.5320)$ & $(.7292)$ \\
Avg. Actual/Predicted Trade Share & 2310 & 2310 \\
\hline
\end{tabular}

Standard errors are reported in parentheses.

$* * *$ significant at $1 \%$ level. 


\section{Appendix III}

Table 1. Ordinary Least Squares. 1970 Trade Flows

\begin{tabular}{|llll|}
\hline \multicolumn{1}{|c}{$\begin{array}{c}\text { Dependent variable } \\
\text { =total trade }\end{array}$} & $\begin{array}{c}\text { Frankel, Stein, } \\
\text { Wei }(1994)\end{array}$ & $\begin{array}{l}\text { Column }(1) \\
\text { recalculated }\end{array}$ & $\begin{array}{c}\text { Adding distance } \\
\text { from WTC }\end{array}$ \\
\hline GNP & $.62^{* * *}(.02)$ & $.72^{* * *}(.02)$ & $.73^{* * *}(.02)$ \\
GNP/Capita & $.45^{* * *}(.03)$ & $.43^{* * *}(.03)$ & $.43^{* * * *}(.03)$ \\
Distance & $-.50^{* * *}(.06)$ & $-.60^{* * *}(.06)$ & $-.68^{* * *}(.06)$ \\
Adjacency & $.68^{* * *}(.17)$ & $.73^{* * *}(.18)$ & $.62^{* * *}(.18)$ \\
Western Hemisphere 2 & $.12(.16)$ & $-.01(.16)$ & $-.15(.17)$ \\
East Asia 2 & $1.75^{* * *}(.29)$ & $1.42^{* * *}(.33)$ & $1.37^{* * *}(.33)$ \\
APEC 2 & $.58^{* * *}(.21)$ & $.61^{* * *}(.22)$ & $.51^{* *}(.22)$ \\
EEC 2 & $-.23^{* *}(.17)$ & $-.44^{* *}(.18)$ & $-.43^{* *}(.18)$ \\
EFTA 2 & $.23(.29)$ & $.27(.30)$ & $.37(.30)$ \\
Western Hemisphere 1 & $-.24^{* *}(.09)$ & $-.12(.09)$ & $-.03(.10)$ \\
East Asia 1 & $.42^{* * *}(.13)$ & $.65^{* * *}(.14)$ & $.62^{* * *}(.14)$ \\
APEC 1 & $-.27 * *(.12)$ & $-.40^{* * *}(.13)$ & $-.36^{* * *}(.13)$ \\
EEC 1 & $.10(.09)$ & $.26 * * *(.09)$ & $.32^{* * *}(.10)$ \\
EFTA 1 & $-.51^{* * *}(.10)$ & $-.33^{* * *}(.11)$ & $-.23^{* *}(.11)$ \\
Distance from WTC & & & $.26^{* * *}(.09)$ \\
No. of obs. & 1274 & 1131 & 1131 \\
Adj. R-sq. & .72 & 0.7584 & 0.7602 \\
Avg. Actual/Predicted Trade & & 1.7136 & 1.7074 \\
Share & & & \\
\hline Standard & & & \\
\hline
\end{tabular}

Standard errors are reported in parentheses.

*significant at $10 \%$ level, **significant at $5 \%$ level, ***significant at $1 \%$ level. 
Table 2. Ordinary Least Squares. 1980 Trade Flows

\begin{tabular}{|c|c|c|c|}
\hline $\begin{array}{l}\text { Dependent variable } \\
=\text { total trade }\end{array}$ & $\begin{array}{l}\text { Frankel, Stein, } \\
\text { Wei (1994) }\end{array}$ & $\begin{array}{l}\text { Column (1) } \\
\text { recalculated }\end{array}$ & $\begin{array}{l}\text { Adding distance } \\
\text { from } W T C\end{array}$ \\
\hline GNP & $\begin{array}{l}.71 * * * \\
(.02)\end{array}$ & $\begin{array}{l}.77 * * * \\
(.02)\end{array}$ & $\begin{array}{l}.79 * * * \\
(.02)\end{array}$ \\
\hline GNP / Capita. & $\begin{array}{l}32 * * * \\
(.23) .\end{array}$ & $\begin{array}{l}33 * * * \\
(.03)\end{array}$ & $\begin{array}{l}.33 * * * \\
(.03)\end{array}$ \\
\hline Distance & $\begin{array}{l}-.58 * * * \\
(.06)\end{array}$ & $\begin{array}{l}-.57 * * * \\
(.05)\end{array}$ & $\begin{array}{l}-.71 * * * \\
(.06)\end{array}$ \\
\hline Adjacency & $\begin{array}{l}.72 * * * \\
(.18)\end{array}$ & $\begin{array}{l}.77 * * * \\
(.17)\end{array}$ & $\begin{array}{l}.56 * * * \\
(.17)\end{array}$ \\
\hline Western Hemisphere 2 & $\begin{array}{l}.86^{* * * *} \\
(.16)\end{array}$ & $\begin{array}{l}.37 * * \\
(.15)\end{array}$ & $\begin{array}{l}.10 \\
(.16)\end{array}$ \\
\hline East Asia 2 & $\begin{array}{l}.64 * * \\
(.26)\end{array}$ & $\begin{array}{l}.68 * * \\
(.29)\end{array}$ & $\begin{array}{l}.51^{*} \\
(.29)\end{array}$ \\
\hline APEC 2 & $\begin{array}{l}1.36 * * * \\
(.19)\end{array}$ & $\begin{array}{l}1.15^{* * *} \\
(.20)\end{array}$ & $\begin{array}{l}1.01 * * * \\
(.19)\end{array}$ \\
\hline EEC 2 & $\begin{array}{l}-.02 \\
(.18)\end{array}$ & $\begin{array}{l}-.18 \\
(.17)\end{array}$ & $\begin{array}{l}-.15 \\
(.17)\end{array}$ \\
\hline EFTA 2 & $\begin{array}{l}.34 \\
(.32)\end{array}$ & $\begin{array}{l}.28 \\
(.30)\end{array}$ & $\begin{array}{l}.55^{*} \\
(.30)\end{array}$ \\
\hline Western Hemisphere 1 & $\begin{array}{l}-.11 \\
(.08)\end{array}$ & $\begin{array}{l}-.12 \\
(.09)\end{array}$ & $\begin{array}{l}-.05 \\
(.09)\end{array}$ \\
\hline East Asia 1 & $\begin{array}{l}.58 * * * \\
(.11)\end{array}$ & $\begin{array}{l}.50 * * * \\
(.12)\end{array}$ & $\begin{array}{l}.48^{* * * *} \\
(.12)\end{array}$ \\
\hline APEC 1 & $\begin{array}{l}-.08 \\
(.11)\end{array}$ & $\begin{array}{l}-.21^{*} \\
(.11)\end{array}$ & $\begin{array}{l}-.16 \\
(.11)\end{array}$ \\
\hline EEC 1 & $\begin{array}{l}.38 * * * \\
(.08)\end{array}$ & $\begin{array}{l}.19 * * \\
(.08)\end{array}$ & $\begin{array}{l}.28 * * * \\
(.08)\end{array}$ \\
\hline EFTA 1 & $\begin{array}{l}-.24 * * \\
(.09)\end{array}$ & $\begin{array}{l}.37 * * * \\
(.09)\end{array}$ & $\begin{array}{l}-.22 * * \\
(.10)\end{array}$ \\
\hline Distance from $W T C$ & & & $\begin{array}{l}.43 * * * \\
(.08)\end{array}$ \\
\hline No. of obs. & 1708 & 1389 & 1389 \\
\hline Adj. R-sq. & .73 & 0.7692 & 0.7740 \\
\hline $\begin{array}{l}\text { Avg. Actual/Predicted } \\
\text { Trade Share }\end{array}$ & & 1.7415 & 1.7191 \\
\hline
\end{tabular}

Standard errors are reported in parentheses

$*$ significant at $10 \%$ level, **significant at $5 \%$ level, ***significant at $1 \%$ level. 
Table 3. Ordinary Least Squares. 1990 Trade Flows

\begin{tabular}{|c|c|c|c|}
\hline $\begin{array}{l}\text { Dependent variable } \\
\quad=\text { total trade }\end{array}$ & $\begin{array}{l}\text { Frankel, Stein, } \\
\text { Wei (1994) }\end{array}$ & $\begin{array}{l}\text { Column (1) } \\
\text { recalculated }\end{array}$ & $\begin{array}{l}\text { Adding distance } \\
\text { from } W T C\end{array}$ \\
\hline GNP & $\begin{array}{l}.73^{* * *} \\
(.02)\end{array}$ & $\begin{array}{l}.81 * * * \\
(.02)\end{array}$ & $\begin{array}{l}.84 * * * \\
(.02)\end{array}$ \\
\hline GNP / Capita & $\begin{array}{l}.17 * * * \\
(.03)\end{array}$ & $\begin{array}{l}.14 * * * \\
(.02)\end{array}$ & $\begin{array}{l}.15^{* * *} \\
(.02)\end{array}$ \\
\hline Distance & $\begin{array}{l}-.66^{* * * *} \\
(.05)\end{array}$ & $\begin{array}{l}-.85^{* * * *} \\
(.06)\end{array}$ & $\begin{array}{l}-.97 * * * \\
(.06)\end{array}$ \\
\hline Adjacency & $\begin{array}{l}.71 * * * \\
(.16)\end{array}$ & $\begin{array}{l}.73 * * * \\
(.17)\end{array}$ & $\begin{array}{l}.55 * * * \\
(.17)\end{array}$ \\
\hline Western Hemisphere 2 & $\begin{array}{l}1.04 * * * \\
(.15)\end{array}$ & $\begin{array}{l}.70 * * * \\
(.15)\end{array}$ & $\begin{array}{l}.45^{* * * *} \\
(.16)\end{array}$ \\
\hline East Asia 2 & $\begin{array}{l}.59 * * * \\
(.23)\end{array}$ & $\begin{array}{l}.26 \\
(.30)\end{array}$ & $\begin{array}{l}.07 \\
(.30)\end{array}$ \\
\hline APEC 2 & $\begin{array}{l}.99 * * * \\
(.17)\end{array}$ & $\begin{array}{l}1.03 * * * \\
(.21)\end{array}$ & $\begin{array}{l}.89 * * * \\
(.21)\end{array}$ \\
\hline EEC 2 & $\begin{array}{l}.17 \\
(.16)\end{array}$ & $\begin{array}{l}-.24 \\
(.18)\end{array}$ & $\begin{array}{l}-.26 \\
(.18)\end{array}$ \\
\hline EFTA 2 & $\begin{array}{l}.11 \\
(.28)\end{array}$ & $.17(.31)$ & $.37(.31)$ \\
\hline Western Hemisphere 1 & $\begin{array}{l}.16^{* *} \\
(.07)\end{array}$ & $\begin{array}{l}.13 \\
(.08)\end{array}$ & $\begin{array}{l}.17 * * \\
(.08)\end{array}$ \\
\hline East Asia 1 & $\begin{array}{l}.89 * * * \\
(.10)\end{array}$ & $\begin{array}{l}.84 * * * \\
(.12)\end{array}$ & $\begin{array}{l}.88 * * * \\
(.12)\end{array}$ \\
\hline APEC 1 & $\begin{array}{l}-.44 * * * \\
(.11)\end{array}$ & $\begin{array}{l}-.18 \\
(.12)\end{array}$ & $\begin{array}{l}-.18 \\
(.12)\end{array}$ \\
\hline EEC 1 & $\begin{array}{l}.12 * * * \\
(.08)\end{array}$ & $\begin{array}{l}.29 * * * \\
(.09)\end{array}$ & $\begin{array}{l}.34 * * * \\
(.09)\end{array}$ \\
\hline EFTA 1 & $\begin{array}{l}-.48 * * * \\
(.09)\end{array}$ & $\begin{array}{l}-.42 * * * \\
(.10)\end{array}$ & $\begin{array}{l}-.31 * * * \\
(.10)\end{array}$ \\
\hline Distance from $W T C$ & & & $\begin{array}{l}.45 * * * \\
(.08)\end{array}$ \\
\hline No. of obs. & 1573 & 1512 & 1512 \\
\hline Adj. R-sq. & .79 & 0.7955 & 0.7997 \\
\hline $\begin{array}{l}\text { Avg. Actual/Predicted } \\
\text { Trade Share }\end{array}$ & & 1.7639 & 1.7344 \\
\hline
\end{tabular}

Standard errors are reported in parentheses

*significant at $10 \%$ level, **significant at $5 \%$ level, ***significant at $1 \%$ level. 